\title{
PLANEJAMENTO URBANO DO CONCEITO A PRÁTICA: O CASO DAS ENCHENTES NO MUNICÍPIO DE FRANCA (SP)
}

\author{
Douglas Parreira Santos ${ }^{1}$
}

Idelvone Mendes Ferreira ${ }^{2}$

\begin{abstract}
RESUMO
O presente trabalho é fruto da pesquisa de nível mestrado que está sendo desenvolvida na cidade de Franca(SP). Buscou-se trazer o objeto de estudo na vertente do Planejamento Urbano e Ambiental, discutindo um de seus problemas dentro desses elementos, as constantes enchentes após eventos chuvosos na área central da cidade. Foram fotografadas algumas das áreas afetadas antes e após os eventos chuvosos para ilustrar o problema e também aguçar a discussão sobre o planejamento da cidade. A forma de ocupação das Três Colinas, como é conhecida a cidade, se deu de forma errônea, inflamado pela impermeabilidade do solo que aumenta o escoamento superficial, fazendo com que o córrego Cubatão transborde e cause danos a sociedade em seu entorno. Outro problema é a canalização do córrego em forma de trapézio, que diminui a calha do córrego, fazendo com que menos metros cúbicos de água possam passar por minuto. $O$ trabalho buscou apresentar esse problema, pois o planejamento incorreto ou a falta dele é notório na maioria das cidades brasileiras, tanto de metrópoles, quanto de cidade de médio porte.
\end{abstract}

PALAVRAS-CHAVE: Planejamento Urbano. Enchentes. Franca(SP)

\section{URBAN PLANNING CONCEPT PRACTICE: THE CASE OF FLOODS IN THE MUNICIPALITY OF FRANCA (SP)}

\footnotetext{
${ }^{1}$ Mestrando em Geografia, Universidade Federal de Goiás (UFG), E-mail. douglas_santos88@yahoo.com.br ${ }^{2}$ Professor Dr em Geografia, Universidade Federal de Goiás (UFG).E-mail. idelvoneufg@gmail.com
} 
Revista Nacional de

Gerenciamento de Cidades

\begin{abstract}
This work é search result of mestrado level that is developed in the city of Franca (SP). Or object is slope study of Planning Urban and Environmental, arguing yours problems problems within elements, as constant after flods events rainy in the central area of the city. Theu were photographed some areas afecteds before rainy to illustrate events or problems and also stimulate to discussion on or planejamento da Cidade. A form of ocupação give three hills, as conhecida é a cidade, deu is so wrong, inflamed impermeabilidade peels do just that increases or superficial flow causing stram Cubatão than or transhipped and cause damage to society. Other problem and to do stream em plumbing in trapeze format, doing fewer cubic meters of water per minute pass. Or work sought present this problem, or absence incorret planning give in most cities Brasileiras, both metropolises, city quantum of medium size.
\end{abstract}

Keywords: Urban Planning. Flood. Franca (SP)

\title{
URBAN PLANNING CONCEPT PRACTICE: THE CASE OF FLOODS IN THE MUNICIPALITY OF FRANCA (SP)
}

\section{RESUMÉN}

Este trabajo es el resultado de nivel de maestría de la investigación que se desarrolla en la ciudad de Franca (SP). Mucha demanda para que el objeto de estudio en el brazo de Urbanismo y Medio Ambiente, discutiendo uno de sus problemas dentro de estos elementos, la inundación constante después de los eventos de lluvia en la zona centro. Ellos fueron fotografiados algunas de las zonas afectadas antes y después de los eventos de lluvia para ilustrar el problema y también agudizar la discusión de la planificación de la ciudad. La forma de ocupación de las Tres Colinas, es conocida como la ciudad se le dio erróneamente, inflamado por la impermeabilidad de la planta que aumenta la escorrentía, provocando el flujo de Cubatao desbordamiento y causan daño a la sociedad que les rodea. Otro problema es la canalización de la corriente en una forma trapezoidal, lo que reduce la corriente de canalón causando menos metros cúbicos de agua puede pasar a través minuto. El trabajo trató de presentar este problema porque la planificación equivocado o la falta de ella es notoria en la mayoría de las ciudades brasileñas, ambas ciudades, como de la ciudad de tamaño medio.

PALABRAS CLAVE: Planificación Urbana. Inundaciones. Franca (SP)

\section{INTRODUÇÃO}

A falta de um Planejamento Urbano prévio e duradouro é marca da política brasileira e do sistema em que estamos inseridos, o que resulta em vários problemas para a sociedade, como; alagamentos; aterros irregulares; 
Revista Nacional de

Gerenciamento de Cidades

impermeabilização excessiva; desmatamento; assoreamento de mananciais; desagregação das encostas; contaminação de mananciais superficiais e subterrâneos, falta de abastecimento de água dentre outros. Em todas as esferas da sociedade o mal planejamento, ou a falta dele, tem reflexo também na academia e na ciência geográfica.

O planejador urbano não pode ser restrito a uma disciplina ou ciência específica. Ninguém no Brasil se forma planejador urbano, mas se torna um planejador urbano (Duarte, 2007). Tendo essas palavras como norte, entende-se que o sucesso do planejamento urbano é a integração de profissionais de diversas áreas como; Geografia, Biologia, Engenharias, Sociologia, Economia, Direito, Administração, Arquitetura e etc. Além disse é de extrema importância a participação do Estado e da população em geral, com o planejamento participativo. É de suma importância que o planejador trabalhe de forma holística e integrada, para a obtenção de melhores resultados

Para adentrarmos a discussão nos elementos que integram o Planejamento Urbano, é necessário que entendamos sua conceituação. $O$ conceito de Planejamento Urbano esteve sempre relacionado à outros termos como; desenho urbano, urbanismo e gestão urbana, todos esses elementos tem como objeto de estudo: a cidade.

\section{ELEMENTOS PARA UM PLANEJAMENTO EFICAZ}

A cidade é um órgão vivo e está em constante transformação e movimento, portanto não se pode avaliar, ou planejar a cidade sem antes entender todos elementos que integram a mesma. Basicamente a cidade possui características físicas, sociais, culturais, políticas e econômicas, portanto todos esses componentes, necessitam de uma atenção, antes de se executar uma ação dentro da cidade. 


\title{
Revista Nacional de
}

O planejamento é crucial para a configuração do espaço urbano, ou seja, do uso do solo urbano. A partir dele é possível, avaliar, prevenir, identificar e valorizar os processos benéficos e minimizar os de aspecto negativo. Infelizmente na política atual o termo "Planejamento" tem sido trocado pelo termo "gestão", o que mostra a falta de entendimento dos gestores da cidade a respeito do conceito. A gestão é um momento posterior ao planejamento e deve ser encarado dessa forma, não como ação de substituição, como acontece. Souza (2011, p. 31) reforça o problema da substituição do termo e do enfraquecimento do planejamento:

\begin{abstract}
O enfraquecimento do planejamento se faz acompanhar pela popularização do termo gestão (nos países de língua inglesa, management), o que é muito sintomático: como a gestão significa a rigor, a administração dos recursos e problemas aqui e agora, operando, portanto, no curto e no médio prazos, o hiperprivilegiamento da idéia de gestão em detrimento de um planejamento consistente representa o triunfo do imediatismo e da miopia dos ideólogos ultraconservadores do "mercado livre". Em outras palavras ele representa a substituição de um "planejamento forte", típico da era fordista, por um "planejamento fraco" (muita gestão e pouco planejamento) [...]. (SOUZA, 2011, p. 31)
\end{abstract}

Essa substituição não apenas conceitual, mas estrutural do planejamento urbano, desestabiliza os elementos que interligam as ações do planejamento, fazendo com que o mesmo seja "impotente". É importante ressaltar que esse tipo de planejamento explanado pelo autor, também pode ser tendencioso, as ações de intervenção no espaço urbano das cidades para beneficiar o setor privado, ou classes dominantes, está também vinculado à esse tipo de "gestão".

Também é resultado dessa substituição de termos a incompreensão da natureza dos mesmos. Os dois termos possuem referenciais temporais distintos e contemplam diferentes tipos de atividades. $O$ ato de planejar sempre remete ao futuro, significando tentar prever a evolução de um dado fenômeno, ou ainda simular os desdobramentos de um processo, com objetivo de melhor precaver-se contra prováveis problemas. Por outro lado a gestão remete ao presente, gerir significa administrar uma situação dentro dos marcos dos recursos presentemente 


\title{
Revista Nacional de
}

Gerenciamento de Cidades

disponíveis, priorizando as necessidades imediatas. Souza (2011, p. 46) finaliza dizendo:

\begin{abstract}
O planejamento é a preparação para a gestão futura, buscando-se evitar ou minimizar problemas, e ampliar margens de manobra; e a gestão é a efetivação ao menos em parte (pois o imprevisível e o indeterminado estão sempre presentes, o que torna a capacidade de improvisação e a flexibilidade sempre imprescindíveis), das condições que o planejamento feito no passado ajudou a construir. Longe de serem concorrentes ou intercambiáveis, planejamento e gestão são distintos e complementares. (SOUZA, 2011, p. 46.)
\end{abstract}

Segundo o mesmo autor, o planejamento é um componente de qualquer ação embasada programaticamente e voltada para a mudança social construtiva. Discorda-se do autor nesse aspecto, pois o planejamento das cidades, não tem cunho social, mas sim visa satisfazer interesses de classes dominantes e do mercado, principalmente o imobiliário. O urbanismo assim, foi se construindo como uma prática, que envolve necessariamente o Estado, por meio de poder da norma e da força sobre o espaço, apoiando interesses das classes dominantes.

Para Henri Lefebvre o urbanismo constitui uma ilusão e uma ideologia, já que os urbanistas, nesse caso os "planejadores", ou "gestores", não partem das práticas urbanas para desvendar a cidade, mas de uma representação da cidade, negando a mesma como produto social, ou seja, negando seus conteúdos sociais, políticos, culturais e econômicos, todos elementos que compõe a cidade e que foram criados pelo homem. $O$ autor ainda alerta para o discurso tecnocrático, que dissemina a impressão de que são capazes de controlar a cidade, principalmente o que é considerado nefasto ou abominante, no caso; lixo, doenças, degradação, transito, violência, criminalidade e etc.

Esse discurso tem como intuito camuflar a verdadeira intenção do "planejamento urbano", a produção da cidade que mostra-se preocupada com os interesses sociais, na verdade esconde as intenções perversas do Estado e do mercado para a acumulação de capital: 


\title{
Revista Nacional de
}

Gerenciamento de Cidades

\begin{abstract}
O capitalismo parece esgotar-se. Ele encontrou um novo alento na conquista do espaço, em termos triviais na especulação imobiliária, nas grandes obras (dentro e foda das cidades), na compra e na venda do espaço. $E$ isso à escala mundial. [...] $O$ urbanismo encobre essa gigantesca operação. Ele dissimula seus traços fundamentais, seu sentido, sua finalidade. Ele oculta, sob uma aparência positiva, humanista, tecnológica, a estratégias capitalista: o domínio do espaço, a luta contra a queda tendencial do lucro médio etc". (LEFEBVRE, 2004, p. 143)
\end{abstract}

Para todos os efeitos, concorda-se com o autor nesse aspecto da perversidade do sistema, em camuflar suas reais intenções para com o uso do espaço urbano nas cidades. Dessa forma, entende-se que o urbanismo ao buscar eficiência e a garantia de funcionamento da cidade, almeja contemplar usos produtivos na cidade. É evidente que o Estado possui o monopólio da violência, da coação e do território, e com isso disciplina o uso da cidade. Com isso o urbanismo usa o discurso técnico para manter ou renovar os usos do solo urbano, o que justifica a segregação socioespacial e oculta os interesses econômicos e as ações dominantes do Estado.

Nesse contexto observa-se que o "planejar" a cidade, também se tornou um fator lucrativo dentro do sistema complexo das cidades. $O$ ato de planejar, também possibilita $\mathrm{o}$ ato de dominar a cidade, estruturalmente, politicamente $\mathrm{e}$ economicamente, inflamando mais os problemas sociais urbanos.

Embasando-se nesse cenário Harvey (2006), nos alerta sobre 0 "planejamento mercadológico" ou, "planejamento estratégico". Para o autor ele representa a adoção de políticas neoliberais no plano da cidade, fazendo com que se perca a perspectiva de regulamentação da cidade, a fim de buscar intervenções estratégicas, desconsiderando de que essas ações possam provocar uma alteração na dinâmica da cidade (valorização/desvalorização, fluxos de pessoas, circulação de mercadoria e de capital).

Nota-se que esse domínio existente nas cidades brasileiras é resultado de um déficit no campo interdisciplinar e intelectual do planejamento urbano. 
Revista Nacional de

Gerenciamento de Cidades

O fato é que a cidade se mostra independente aos olhos das pessoas, mas é totalmente dominada pelos interesses das classes dominantes e do Estado. Segundo Rodrigues (2013) é preciso superar o "estadocentrismo" que domina e que faz tratarem o planejamento urbano e os movimentos sociais, ou a sociedade civil, como entidades separadas e inconciliávei8s. O Estado não pode ser o único agente do espaço urbano a planejar, como já foi dito, os interesses do mercado e do Estado, estão longe dos reais interesses da população que habita as cidades, e do que realmente a cidade precisa.

É importante se destacar os momentos do Planejamento Urbano, a fim de entender cada procedimento adotado, e a importância de cada elemento para que o resultado seja satisfatório sócioespacialmente. Inicia-se 0 pensamento primeiramente com duas questões: para que planejar? e para quem planejar? Esses dois questionamentos nortearão os demais momentos do processo de planejamento urbano nas cidades e auxiliará para que haja uma significativa diminuição na segregação socioespacial. O segundo pensamento implica-se em conscientizar-se sobre os recursos disponíveis para a execução da ação. Cintra (1974) disserta que o planejamento urbano define-se como "bem público de segundo grau":

Consistindo os bens públicos na internalização de consequências indiretas da produção de bens privados, o planejamento seria encarado como meio adequado de fazer com que os bens públicos fosses produzidos na quantidade e qualidade demandadas, no tempo oportuno e de modo tal que, na obtenção singular de cada um deles, as interdependências com os outros fossem levadas em consideração, para maior eficiência no uso de recursos disponíveis. Nesse sentido justifica-se a ideia de que continua um bem público de segundo grau, pois visa a resultados não espontaneamente obtidos pelas ações isoladas dos agentes públicos na produção de bens coletivos singulares. (CINTRA, 1974, p. 116-117)

As ações dos agentes do espaço urbano para planejar uma área ou um local da cidade, se baseia na produção de bens de primeiro grau, ou seja, serviços, equipamentos e benefícios para os poderes públicos e agentes dominantes, e em segundo lugar para o restante da população da cidade. Sobre esse assunto o mesmo autor completa que nas sociedades de classes, próprias do capitalismo, o 
Revista Nacional de

Gerenciamento de Cidades

maior dilema enfrentado pelo planejamento é o da igualdade vs desigualdade na repartição dos benefícios coletivos.

Salienta-se aqui que esse é um dos procedimentos de mudança propostos na pesquisa, para que haja uma mudança na forma de planejar e diminuir os problemas socioespaciais na cidade, sabe-se que apenas essas duas questões sozinhas não resolverão o problema. Chama-se a atenção também para as políticas municipais que são de extrema importância para uma execução de planejamento adequado.

As políticas municipais que tem como resultado concreto as interferências no espaço, implicam a instituição de um tempo. Muitas vezes as implicações futuras dessa conduta acontecem sem nenhuma priorização de atividades, o que segundo Pintaudi (2001) resulta em inúmeras intervenções desconexas e sem possibilidades duráveis.

Os momentos do Planejamento Urbano basicamente se dividem em: Diagnóstico, Prognóstico, Propostas e Gestão Urbana. O diagnóstico é a análise de uma situação, compondo um cenário de realidade existente. Desse modo, toda análise depende de dados, disponíveis, ou a serem coletados. Um exemplo dessa ação é fazer uma análise de uma dada cidade, sobre o número de habitantes, taxa de crescimento da população nos últimos anos, fluxos migratórios e etc.

Essas informações auxiliarão no banco de dados do planejamento, é importante explanar que os dados precisam estar de acordo com o que será proposto no planejamento, por exemplo saber quantos carros existem na cidade, para uma ação que será feita para recuperação da margem de um córrego, essa informação não será interessante para o procedimento.

O segundo momento é o Prognóstico, sua função é preparar o planejamento para que o mesmo seja futuramente equilibrado, embasando-se nos dados do momento anterior. Visivelmente esse é um fator importante no Planejamento Urbano, mas que não acompanha a maioria dos projetos dos mesmos. É importante 


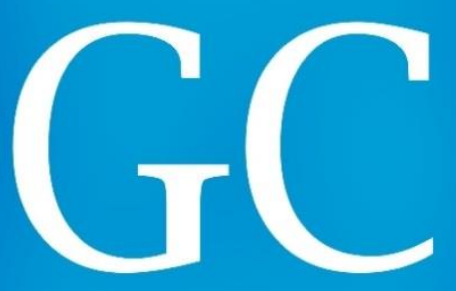

Revista Nacional de

Gerenciamento de Cidades

que se tenha um estudo prévio sobre a cidade, antes de se intervir no espaço da mesma.

O crescimento desigual das cidades brasileiras é reflexo de uma falta desses estudos, sobre crescimento populacional, áreas não habitáveis e etc. O planejamento no Brasil tem efeito remediador e não preventivo como é preciso ser.

Planeja-se obras e ações no espaço urbano para o presente, não pensando nas futuras consequências. Para exemplificar esse fato, e para suprir a proposta da pesquisa em trazer realidades do objeto de estudo para o referencial teórico, a fotografia abaixo mostra a canalização e a impermeabilização do Córrego do Cubatão, feita na década de 1960, quando a cidade de Franca(SP) obtinha 93.613 habitantes ${ }^{3}$.

Figura 1 - Canalização do Córrego Cubatão em Franca(SP)

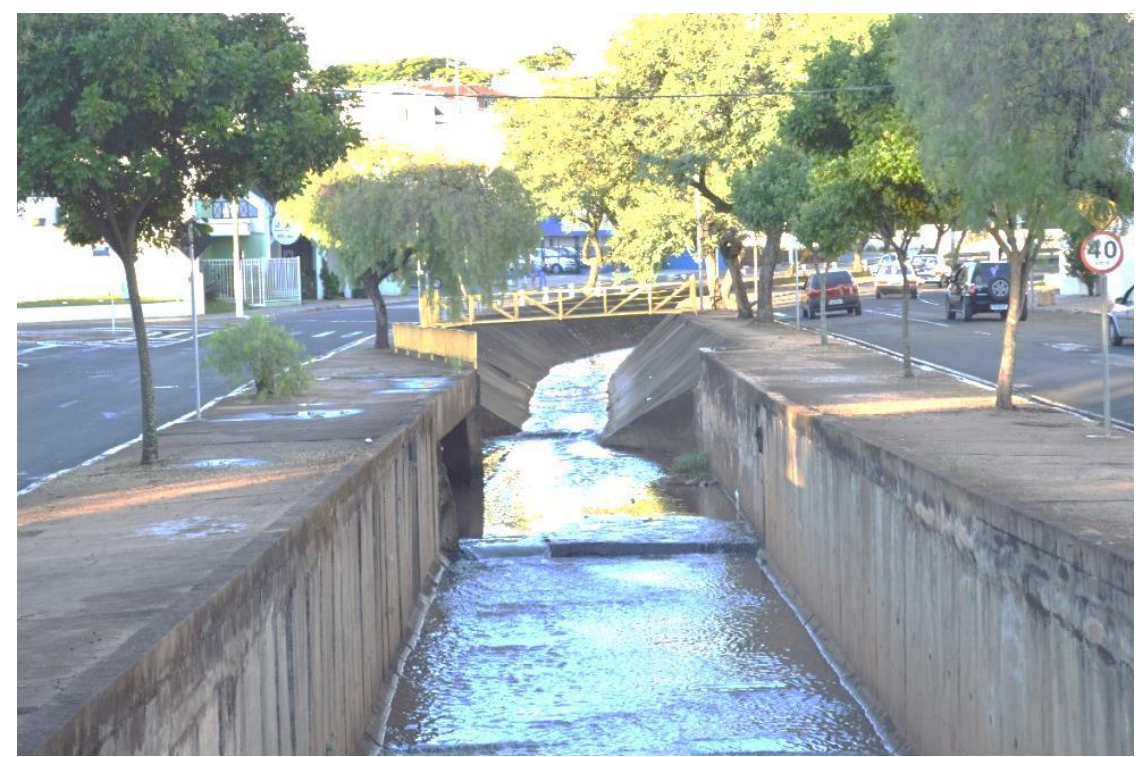

Fonte: SANTOS, D.P. 2015. Arquivo Pessoal

\footnotetext{
${ }^{3}$ Fonte: F.I.B.G.E (Fundação Instituto Brasileiro de Geografia e Estatística). Censos Demográficos: Série Regional - São Paulo (1960).

Observação: Nessa data as cidades de Restinga (1964) e Ribeirão Corrente (1946), faziam parte do município de Franca(SP). Em parênteses as datas de autonomia das mesmas.
} 


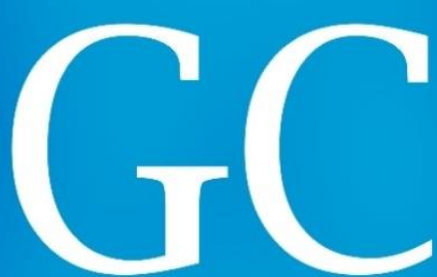

Revista Nacional de

Gerenciamento de Cidades

Além disso o Córrego Cubatão, foi canalizado em forma de trapézio, como pode-se observar na foto. Essa forma de canalização dificulta ainda mais o escoamento da água, fazendo que o volume do córrego suba rapidamente em eventos chuvosos. Outro fator que agrava a questão das enchentes nessa região da cidade é a impermeabilização do solo. A área central da cidade de Franca(SP) está quase totalmente impermeabilizada, o que dificulta a infiltração da água no solo e aumenta o escoamento superficial ${ }^{4}$.

Figura 2 - Avenida Ismael Alonso Y Alonso sem eventos chuvosos

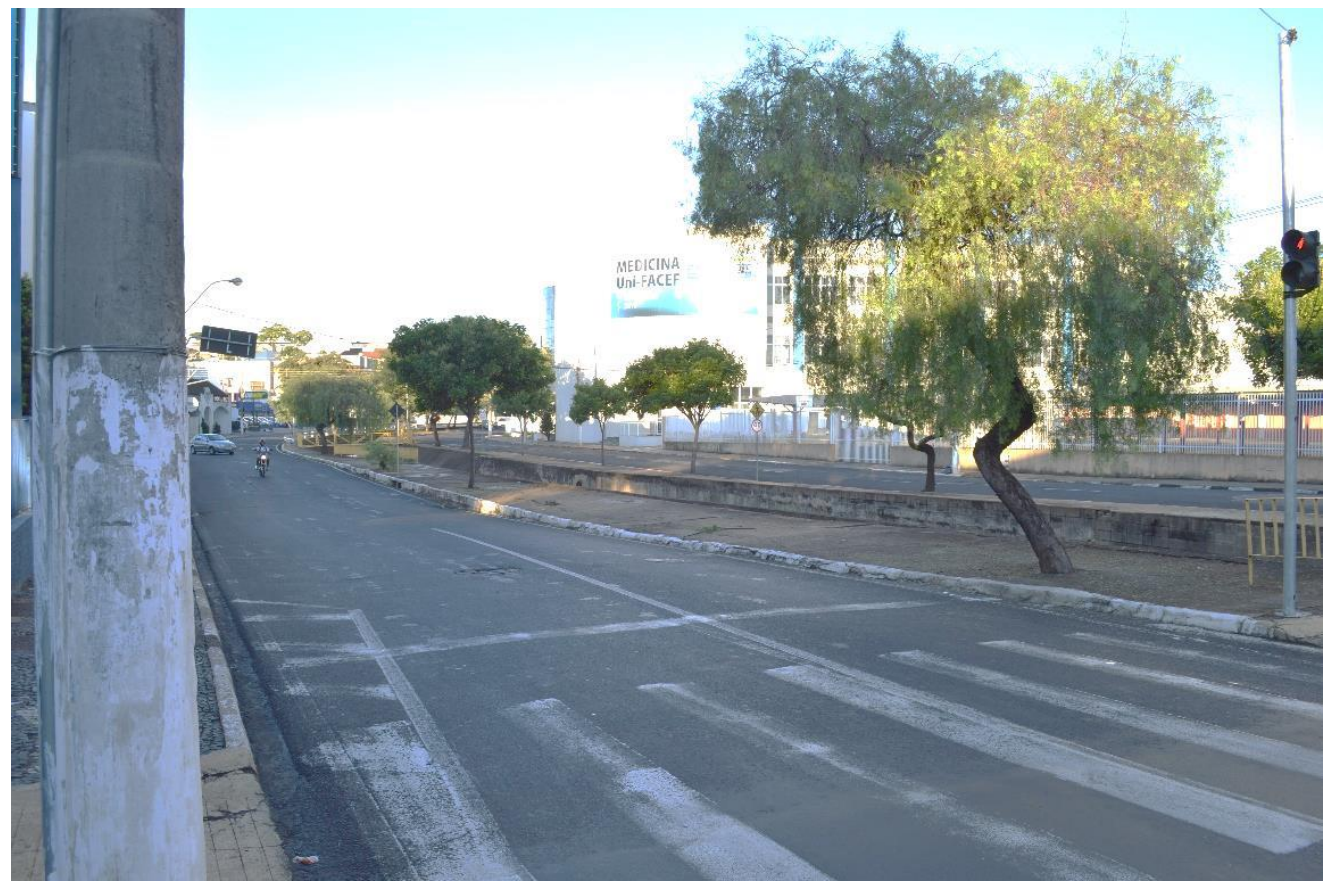

Fonte: SANTOS, D.P. 2015. Arquivo Pessoal.

Reflexo disso são as constantes inundações dos córregos da cidade, em eventos chuvosos, trazendo prejuízos para a população. Segundo o senso do IBGE (Instituto Brasileiro de Geografia e Estatística) em 2014 a população da cidade de Franca(SP) será de 339.461 habitantes (estimativa para o ano de 2014), um aumento

\footnotetext{
${ }^{4}$ Para maior aprofundamento teórico sobre impermeabilização do solo urbano e drenagem urbana consultar: CANHOLI, A. P. Drenagem urbana e controle de enchentes. São Paulo: Oficina de Textos, 2015.
} 


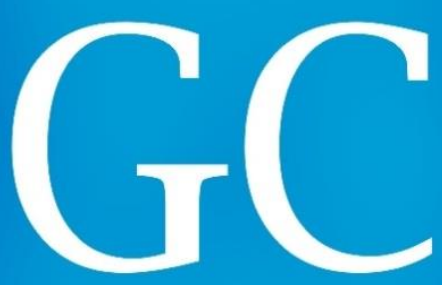

Revista Nacional de

Gerenciamento de Cidades

de $262 \%$ em cinquenta e quatro anos com crescimento médio de $4,85 \%$ ao ano. $\mathrm{Na}$ foto 3 o Córrego do Cubatão no ano de 2014, após um evento chuvoso.

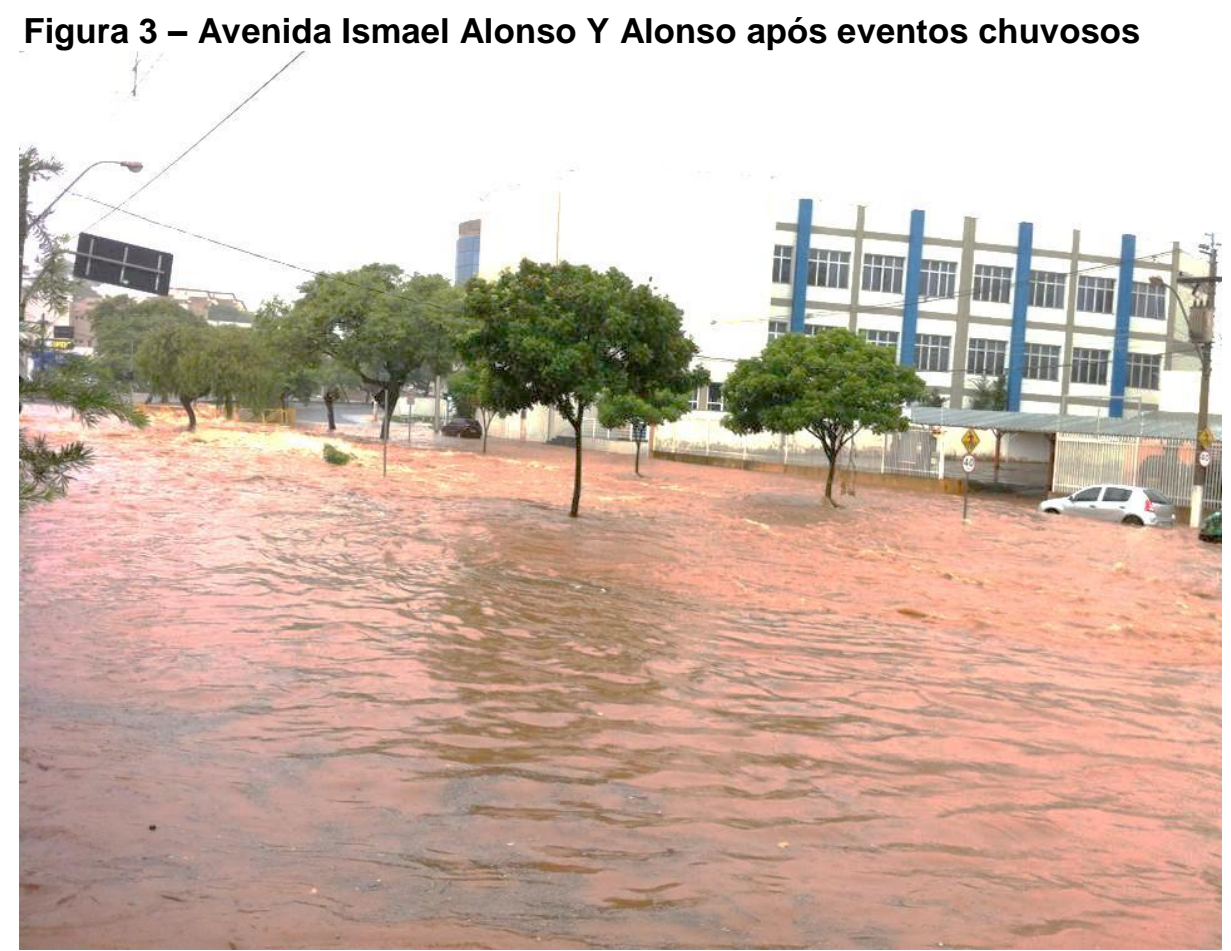

Fonte: SANTOS, D. P. 2015. Arquivo Pessoal.

Foi usado como exemplo de prognóstico o objeto de estudo, a fim de ilustrar a importância do processo, que muitas vezes é "esquecido" pelos planejadores no Brasil. A impermeabilização dos Córregos na cidade de Franca(SP) na década de 1960 não adotou essas medidas, e o reflexo disso anos depois, como ilustrado na foto a cima, é o constante alagamento dos córregos (Cubatão, Espraiado e dos Bagres). ${ }^{5}$

\footnotetext{
${ }^{5}$. Para mais informações sobre as enchentes na cidade de Franca consultar: Santos, D. P. Meio Ambiente: Perspectivas e Desafios no Município de Franca(SP). In anais - VI CIETA Congresso IberoAmericano de Estudios Territoriales e Ambientales. São Paulo. 2014.

Sobre a expansão urbana e o planejamento urbano na cidade de Franca(SP) consultar: Chiquito, E. A. Expansão Urbana e Meio Ambiente nas cidades não-metropolitanas: o caso de Franca-SP. São Carlos, 2006. Dissertação de Mestrado.
} 


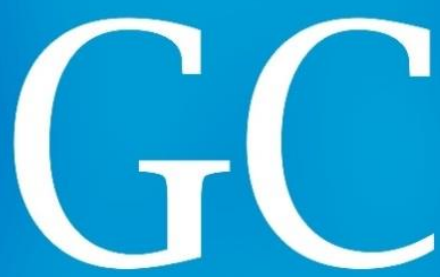

Revista Nacional de

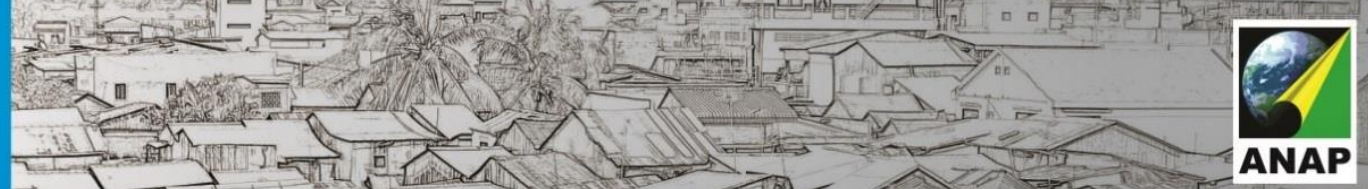

Gerenciamento de Cidades

Essas enchentes causam vários prejuízos para a sociedade, nessa área da cidade as enchentes afetam principalmente a Faculdade de Direito de Franca (FDF), que se localiza do lado esquerdo da fotografia, Centro Universitário de Franca (UniFACEF), e o antigo Fórum Comarca de Franca (figura 4), o mais prejudicado pelas enchentes. Aulas são suspensas sempre que as chuvas são constantes, para preservar a segurança dos alunos e professores das faculdades.

Figura 4 - Prédio do Fórum Comarca de Franca(SP) após eventos chuvosos

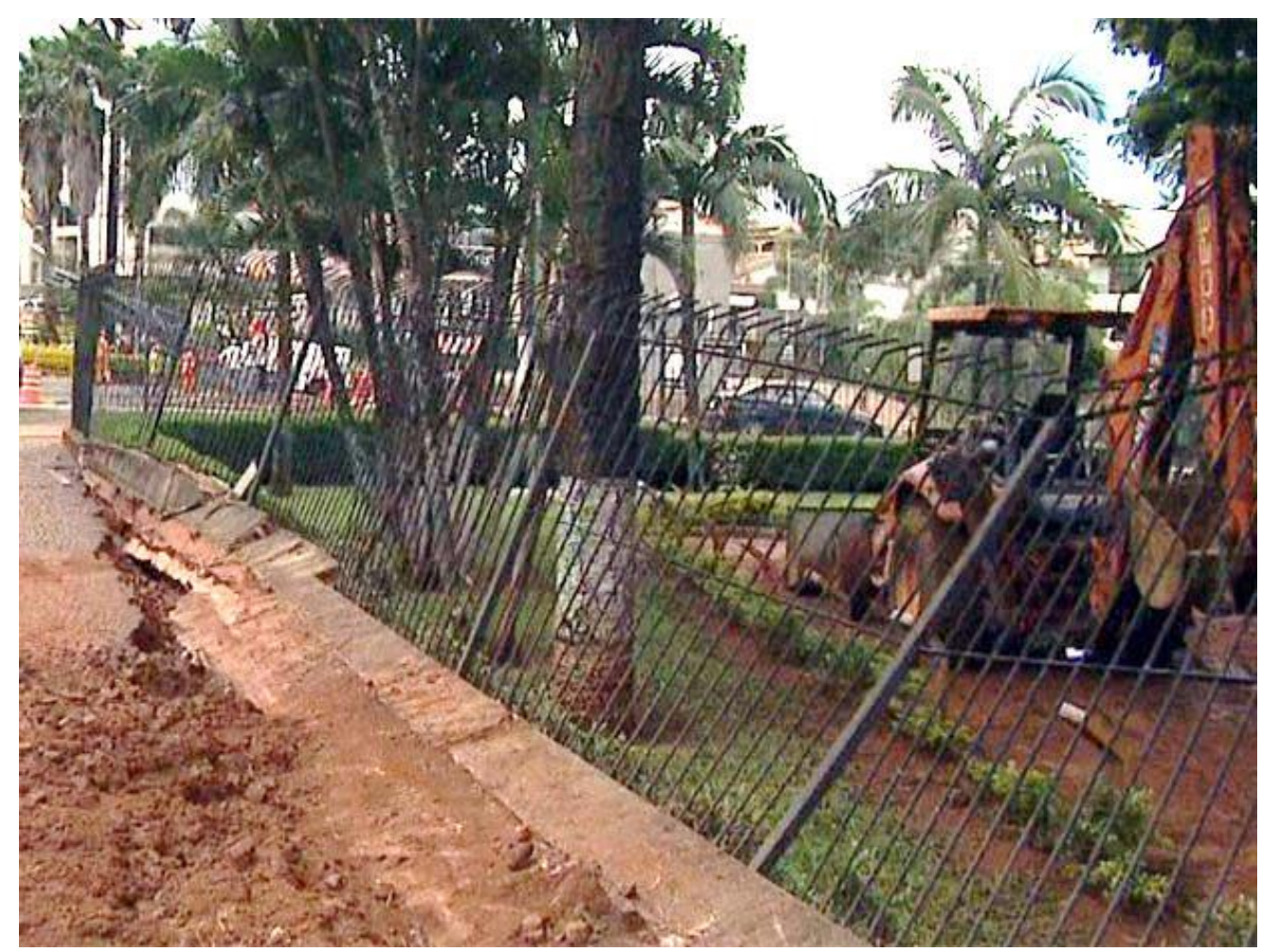

Fonte: SANTOS, D.P. 2015. Arquivo Pessoal.

O Fórum de Franca (SP) por diversas vezes já teve suas atividades interrompidas por semanas, por conta dos constantes alagamentos do córrego, fazendo com que haja uma sobrecarga de trabalho (por ser o Fórum referência da região) e perca material de processos, documentos, computadores e etc. 
Revista Nacional de

Gerenciamento de Cidades

O terceiro momento do processo de planejamento são as propostas, são elas que irão tornar o futuro possível. Nessas propostas entram aspectos de obras de infraestrutura de um bairro por exemplo, ou ações no âmbito do desenvolvimento regional. Basicamente ela se divide em dois vetores principais, o vetor previsível e o desejável.

O fator previsível é o resultado do prognostico, são os dados coletados e analisados, tornando possível planejar o local devido a situação que se encontra. $O$ segundo o fator é o desejável, este apenas irá complementar o primeiro, com pequenos ajustes embasados nas perspectivas e diferentes visões do processo. É importante que esse momento seja minunciosamente cautelosa. Para que não haja gastos exacerbados no planejamento. Nas cidades brasileiras é nítido que as obras são superfaturadas, sem necessidade, ou com segundas intenções; lavagem de dinheiro e desvio de verbas. Como já defendido aqui o planejamento urbano precisa ser pautado na qualidade de vida dos indivíduos que nela habita, e não de uma minoria dominante como acontece.

O quarto momento a gestão urbana que segundo Acioly e Davidson (1988) são um conjunto de instrumentos, atividades, tarefas e funções que visam assegurar o bom funcionamento de uma cidade. A gestão urbana deve responder às necessidades e demandas da população e dos vários agentes privados, públicos e comunitários, que tem interesses e pensamentos opostos. Como já discutido anteriormente a gestão não é uma substituição do planejamento, mas é uma etapa da mesma.

Outros autores ainda propõem outros momentos para a elaboração do processo do planeamento urbano, tendo a mesma visão. É o caso de Culling-Worth (1997), que diz que os elementos fundamentais para a elaboração odo planejamento urbano são; a) pensamento orientado para o futuro, b) escolha entre alternativas, c) consideração e limites, restrições e potencialidades; consideração de prejuízos e benefícios e d) possibilidade de diferentes cursos de ação, os quais dependem de condições e circunstancias variáveis. Não diferente de Duarte (2007) e Souza (2001) 
Revista Nacional de

Gerenciamento de Cidades

o autor também mostra-se preocupado com os conflitos de interesse que integram os planejamentos das cidades e fala em reconciliar as partes, fazendo que 0 planejamento seja uma ferramenta harmoniosa.

Concorda-se com o autor que a base do planejamento está na relação de interesses dos diferentes agentes produtores do espaço urbano que o integram. É bem verdade que as classes dominantes e alguns agentes como o Estado e os proprietários imobiliários, estão à frente dos planejamentos e obras dentro da cidade. Seus interesses estão em um patamar mais elevado, embasado no mercado e no sistema vigente. A preocupação social nas cidades não está em pauta para esses agentes, a não ser que vejam em algum local ou obra uma "barganha" para obterem lucro sobre das classes menos favorecidas.

A gestão urbana tem como responsabilidade gerenciar, monitorar e adequar a cidade aos planos propostos e assegurar o seu funcionamento. Essa etapa deve ser feita de forma integrada, assim como as demais, o Estado e os agentes dominantes do espaço urbano intervêm muitas vezes na gestão, fazendo com que seja feita em primeira e unicamente as suas necessidades, deixando de lado as questões sociais da cidade. Planejamento requer consciência social acima de tudo, pois a cidade é feita para os cidadãos e ela e sua casa:

[s]e planejar é sinônimo de conduzir conscientemente, não existirá então alternativa ao planejamento. Ou planejamos ou somos escravos da circunstância. Negar o planejamento é negar a possibilidade de escolher o faturo, é aceita-lo seja ele qual for. (MATUS, 1996, tomo I, p. 14 apud SOUZA, 2011, p. 46)

Planejar a cidade vai além de se construir moradias, casas populares, arranha céus, pontes, viadutos, túneis, parques, áreas verdes, áreas comerciais, áreas industriais, planejar a cidade a cima de tudo é responsabilidade de todos os habitantes da mesma, sejam eles de classes dominantes ou das classes socialmente excluídas. Todos devem ter o direito de reivindicar uma cidade mais saudável, estruturada e promissora. Para esses efeitos, chama-se a atenção para 


\section{Revista Nacional de}

que o planejamento integrado faça parte não só de discursos políticos, mas da empiria do planejamento das cidades.

Santos (2004) comenta que participar significa tomar parte, fazer saber, integrar-se pela razão e pelo sentimento, promover alianças e tomar decisões sobre aquilo que é do uso e direito de todos, na presença de todos. Para Bordenave (1994) o termo participação vem da palavra parte, integrar-se, tomar parte, segundo o autor a participação tem acompanhado história do homem e sua evolução ao longo do tempo. Desde a formação de tribos primitivas, tribos indígenas, até as pólis na Grécia antiga, associações, empresas, partidos políticos, instituições, Organizações não Governamentais (ONG), ou qualquer tipo de organização que fomente em coletividade.

Sendo assim o homem necessita de participar, integrar-se em assuntos da sociedade, pois é um ser social e não vive sozinho na cidade. Entretanto essa participação varia conforme seus interesses. Ir à igreja, à escola, ao supermercado, são atividades cotidianas que o homem moderno desempenha dentro da cidade, como ser social. Essas ações são de obrigatoriamente de sobrevivência, trabalho, renda, moradia, alimento, essas quatro palavras são relacionadas diretamente à vida do homem.

O interesse do homem em outras participações coletivas, varia conforme sua posição na sociedade ou necessidade e interesse nessa relação. A participação coletiva basicamente é representada por alguns membros da sociedade que participam, com voz ativa ou não, das reuniões de planejamento urbano da cidade. É de extrema importância que a sociedade tome parte dos problemas da cidade e junto com os gestores da mesma, entrem em consenso para suprir as necessidades da população em geral.

A participação popular no planejamento urbano das cidades é de extrema importância para o desenvolvimento da mesma, principalmente no quesito social. Os agentes dominantes do espaço urbano, apenas veem seus próprios interesses dentro da cidade, esquecendo dos problemas sociais e ambientais da mesma. 


\section{CONSIDERAÇÕES FINAIS}

Após a coleta inicial dos dados para a pesquisa, constatou-se que o problema na cidade de Franca(SP) para com as constantes enchentes que ocorrem na área central da cidade após eventos chuvosos é de cunho histórico. Desde a instalação das primeiras pessoas e o crescimento das cidades nas partes altas da cidade de forma incorreta, criaram o problema, que hoje é quase irreversível. Apesar dos esforços da Prefeitura Municipal de Franca(SP) para conter as enchentes com obras nos córregos da cidade, os dois principais problemas não foram sanados.

Primeiramente é preciso controlar o escoamento superficial, para que a água infiltre no solo e não corra diretamente para os córregos. Segundo a canalização dos córregos e totalmente de concreto, a água que corre nos córregos não infiltra no solo e terceiro e calha dos córregos são pequenas, a cidade aumentou sua população, ou seja o nível dos córregos também tende a aumentar, com uma alha pequena a quantidade de metros cúbicos que passam por minuto são abaixo da necessária.

De imediato para remediar o problema deve-se aumentar a calha dos córregos lateralmente e em profundidade, para que a água tenha mais espaço para percorrer o caminho até sair da cidade, após essas obras o planejamento de longa data deve ser política na cidade, para que esses eventos não voltem a ocorrer.

\section{REFERÊNCIAS}

BORDENAVE, J. E. D. O que é participação. São Paulo: Brasiliense, 1994.

CANHOLI, A. P. Drenagem urbana e controle de enchentes. São Paulo: Oficina de Textos, 2015.

CHIQUITO, E. A. Expansão Urbana e Meio Ambiente nas cidades não-metropolitanas: o caso de Franca-SP. São Carlos, 2006. Dissertação de Mestrado.

CINTRA, A. C. Nota sobre os condicionantes políticos do planejamento urbano. Cadernos do Departamento de Ciência política, Belo Horizonte, n.2. pg 115 - 138.

PINTAUDI, Silvana Maria. A cidade e as formas do comércio. In: CARLOS, Ana Fani

Alessandri (org.) Novos Caminhos da Geografia. São Paulo: Contexto, 1999. p.143159. 


\section{Revista Nacional de}

\section{Gerenciamento de Cidades}

CULLINGWORTH, J. Barry; NADIN, V. Town \& country planning in the UK. 12th. ed. London: Routledge, 1997.

DUARTE, F. Planejamento Urbano. Curitiba: Ibpex, 2007.

F.I.B.G.E (Fundação Instituto Brasileiro de Geografia e Estatística). Censos Demográficos: Série Regional - São Paulo (1960)

HARVEY, D. A produção capitalista do espaço. São Paulo: Boitempo, 2006.

IBGE Cidades. Disponível em http://www.cidades.ibge.gov.br/. Acesso em 3 abril de 2014.

LEFEBVRE, H. A Revolução Urbana. Belo Horizonte: Ed. UFMG. 2004.

PINTAUDI, S, M. A cidade e as formas do comércio. In: CARLOS, Ana Fani

Alessandri (org.) Novos Caminhos da Geografia. São Paulo: Contexto, 2001. p.143-

159.

RODRIGUES, A. M. Loteamentos Murados Condominios fechados: Propriedade Fundiária Urbana e Segregação Socioespacial. In. VASCONCELOS, P. A; CORRÊA, R. L; PINTAUDI, S. M (orgs). A cidade Contemporânea: Segregação Espacial. São Paulo: Contexto, 2013. pg 147 - 168.

SANTOS, D. P. Meio Ambiente: Perspectivas e Desafios no Município de Franca(SP). In anais VI CIETA Congresso Ibero-Americano de Estudios Territoriales e Ambientales. São Paulo. 2014. SANTOS, R. F. Planejamento ambiental: teoria e pratica. São Paulo: Oficina de Textos, 2004.

SOUZA, M. Mudar a cidade: uma introdução crítica ao planejamento e à gestão urbanos. $-8^{\text {a }}$ ed. Rio de Janeiro: Bertrand Brasil, 2011.

SOUZA, M. O território: sobre espaço e poder, autonomia e desenvolvimento. In: CASTRO, I, E; CORRÊA, R e GOMES, P. (Orgs.) Geografia: conceitos e temas. 3 ed.

Rio de Janeiro, Bertrand Brasil, 2001. p. 77-116. 